\title{
Characterization and Antimicrobial Activity of Silver Doped Hydroxyapatite Obtained by the Microwave Method
}

\author{
Meruyert KOIZHAIGANOVA ${ }^{1 *}$, Ihsan YAŞA ${ }^{2}$, Gürbüz GÜLÜMSER ${ }^{3}$ \\ ${ }^{1}$ Denizli Vocational School of Technical Sciences, Pamukkale University, Kınıkl, Denizli 20013, Turkey \\ ${ }^{2}$ Basic and Industrial Microbiology Department, Basic Science Faculty, Ege University, Bornova, Izmir 35100, Turkey \\ ${ }^{3}$ Leather Engineering Department, Engineering Faculty, Ege University, Bornova, Izmir 35100, Turkey \\ cross $^{\text {ref }}$ http://dx.doi.org/10.5755/j01.ms.22.3.12133
}

Received 27 April 2015; accepted 20 August 2015

\begin{abstract}
In this study, silver ( $\mathrm{Ag}$ ) doped hydroxyapatite (HA) was produced by the microwave method and its antimicrobial activity was investigated. The physical, chemical and structural characteristics of the material were determined using multi-purpose X-ray diffractometry (XRD), Fourier transform infrared spectrometry (FTIR), and scanning electron microscope-energy dispersive X-ray spectroscopy (SEM-EDS) apparatus. The amount of silver in the solutions of silverdoped hydroxyapatite obtained were determined with the use of an inductively coupled plasma optical emission spectroscopy instrument (ICP-OES). The minimum inhibition concentration (MIC) of the silver doped hydroxyapatite (Ag-HA) against the test microorganisms was determined by the Broth Microdilution method. It was established that a concentration of $2.09-12.25 \mu \mathrm{g} / \mathrm{ml}$ was effective against gram-negative bacteria (Escherichia coli ATCC 12228, Salmonella typhimurium CCM 5445, Pseudomonas aeruginosa ATCC 27853, Klebsiella pneumoniae CCM 2318), and $4.18-12.25 \mu \mathrm{g} / \mathrm{ml}$ was effective against gram-positive bacteria (Staphylococcus aureus ATCC6538-P, Bacillus subtilis ATCC 6633, Enterococcus faecalis ATCC 29212) and the yeast Candida albicans ATCC 10239.

Keywords: silver, hydroxyapatite, microwave, MIC value, antimicrobial activity.
\end{abstract}

\section{INTRODUCTION}

The importance of antimicrobial ceramics, which are used widely in factories, building materials, cosmetics and electrical appliances, is steadily increasing. These materials need to have a supporting structure to which metal ions can easily be added. The basal material can be classified as amorphous silica, zeolite or calcium phosphate, which shares the characteristic of a broad crystal structure. Thanks to this, the metal ions enter the system and affect microorganisms [1, 2].

Calcium phosphate, known as hydroxyapatite (HA) has the structural formula $\mathrm{Ca}_{10}\left(\mathrm{PO}_{4}\right)_{6}(\mathrm{OH})_{2}$. Several chemical and thermal methods have been developed to produce this compound in the form of ceramic powder $[3,4,5]$. Because of the calcium and phosphorus which it contains, HA has a high level of compatibility with the human body, and as a result is used in various parts of the body as an implant. At the same time, the exchange rate of metal cations such as $\mathrm{Ag}^{1+}, \mathrm{Cu}^{2+}, \mathrm{Zn}^{2+}$ in $\mathrm{HA}$ is very rapid [6].

It has long been known that silver and silver ions have a strong antimicrobial effect. Because of this effect and because they are non-toxic, silver ions are applied as an additive to coating materials to the surfaces of many items such as ceramics, glass, tilework, plastic, paper, paint or textiles which are in daily use, but have many microorganisms, either at the time of manufacture or later [2].

Silver doped HA (Ag-HA) can be obtained by various methods such as chemical precipitation, sol-gel and ion

\footnotetext{
* Corresponding author. Tel.: +90 258212 3788; fax: +90 2582118065. E-mail address: meruyert_k@hotmail.com (M. Koizhaiganova)
}

exchange $[7,8,9]$. However, in the present study it was obtained by a different method using microwaves, and the antimicrobial effect of the Ag-HA obtained was tested by the Broth Microdilution method against eight microorganisms [10].

\section{MATERIALS AND METHOD}

\subsection{Preparation and characterization of $\mathrm{Ag}-\mathrm{HA}$ solutions}

In the preparation of Ag-HA solutions, calcium hydroxide $\left(\mathrm{Ca}(\mathrm{OH})_{2}\right)$, diammonium hydrogen phosphate $\left(\left(\mathrm{NH}_{4}\right)_{2} \mathrm{HPO}_{4}\right)$ and silver nitrate $\left(\mathrm{AgNO}_{3}\right)$ were used as precursor materials. Ultra pure water was used as a solvent in the experiments.

Solutions of pure HA and Ag-HA were prepared by the microwave method according to [11]. $\mathrm{AgNO}_{3}(0.25 \mathrm{M})$ was dissolved in pure water at room temperature. Then a $0.3 \mathrm{M}$ suspension of calcium hydroxide was prepared in a different glass flask by mixing with pure water. Following this, the silver nitrate solution was added dropwise to the calcium hydroxide suspension and $0.3 \mathrm{M}$ diammonium phosphate was added to this solution, with five minutes of strong stirring. The prepared solution was then exposed to 30 minutes of heat treatment in a microwave oven $(800 \mathrm{~W}$, $2.5 \mathrm{GHz}$ ). In this way, colloidal hydroxyapatite solutions containing various concentrations of silver $(0.5-5 \%)$ were obtained, and were used in the subsequent tests. In order to perform characterization analyses, the Ag-HA solutions were dried at $100{ }^{\circ} \mathrm{C}$ for 12 hours in a drying oven and ground to a powder in a mortar. Pure hydroxyapatite, which was used as a control, was prepared by the same method but without the addition of silver nitrate. 
The physical, chemical and structural characteristics of the materials obtained were determined by means of X-ray diffractometry (XRD, Philips), Fourier transform infrared spectrometry (FTIR, Perkin Elmer) and Scanning electron microscope-Energy dispersive X-ray spectroscopy instruments (SEM-EDS). For phase analysis, XRD of samples was carried out under $\mathrm{Cu}-\mathrm{Ká}$ radiation and data were taken at a rate of $2 \% \mathrm{~min}$ scanned at $2 \theta=10^{\circ}-70^{\circ}$ interval. The structure of the HA and Ag-HA powders was determined by FTIR spectrum scanning in the range of $4000-400 \mathrm{~cm}^{-1}$. Scanning electron microscope (JEOL JSM-6060) was used to determine the surface morphology of the hydroxyapatite powders. The amount of silver in the hydroxyapatite solutions obtained was determined by means of an inductively coupled plasma optical emission spectroscopy (ICP-OES, Perkin Elmer) instrument.

\subsection{Determination of MIC values of hydroxyapatite solutions}

In order to establish the in vitro antimicrobial activity of the $0-5 \%$ solutions of Ag-HA prepared, the Grampositive bacteria Escherichia coli ATCC 12228, Salmonella typhimurium CCM 5445, Pseudomonas aeruginosa ATCC 27853, Klebsiella pneumoniae CCM 2318; the Gram-negative bacteria Staphylococcus aureus ATCC6538-P, Bacillus subtilis ATCC 6633, Enterococcus faecalis ATCC 29212 and the yeast Candida albicans ATCC 10239 were used. The minimum inhibition concentrations (MIC) of the solutions were determined with 96-well microplates using the Broth Microdilution technique [10]. Activation of microorganisms was obtained by incubation in Müller Hinton Broth (MHB) at $37{ }^{\circ} \mathrm{C}$ for $18-20$ hours $[12,13,14]$.

The $0-5 \%$ Ag-HA solutions were tested in a doubly diluted form. A certain aliquot of each dilution and MHB containing each test microorganism were poured into each well to make the wells up to $200 \mu \mathrm{L}$. After 24 hours of incubation, $50 \mu \mathrm{L}$ of $0.5 \%$ TTC (triphenyl tetrazolium chloride) was added on top of the cells, and incubation was continued for another two hours. At the end of this period, the red formazan compound formed by the reduction of the TTC was accepted as an indicator of reproduction, and used to determine the MIC value [15]. The MIC was determined as the lowest concentration that inhibited the visible growth of the test microorganism.

\section{RESULTS AND DISCUSSION}

\subsection{X-ray diffraction phase}

Fig. 1 shows the XRD diffraction patterns for the pure $\mathrm{HA}$ and Ag-HA powders. The peaks in these graphs were compared with data in the JCPDS catalogue [16] and they showed characteristic peaks which were consistent with the peaks given for hydroxyapatite by the International Diffraction Data Centre. Here, the characteristic peaks of the solid phases of HA formed by the pure HA ceramic $\left(2 \theta \sim 25-34.5^{\circ}\right)$ clearly showed the development of a weak crystallized apatite phase. It was clearly seen that all the peaks relating to hydroxyapatite in the powder samples in Fig. 1 at $2 \theta$ were generally at $25.80^{\circ}, 28.60^{\circ}$, and $32.10^{\circ}$. In addition, at $2 \theta$, low density peaks were found at $34.20^{\circ}, 39.60^{\circ}, 46.50^{\circ}$ and $49.00^{\circ}$. In the XRD results of HA samples with $5 \% \mathrm{Ag}$, the characteristic peaks of silver oxide $\left(\mathrm{Ag}_{2} \mathrm{O}\right)$ were observed along with those of hydroxyapatite.

Chung et al. observed that the phase characteristic of $\mathrm{HA}$ formed when it calcined at a temperature of $350{ }^{\circ} \mathrm{C}$, and that $\mathrm{Ag}_{2} \mathrm{O}$ and $\mathrm{CaO}$ peaks appeared when the amount of Ag was $20000 \mathrm{ppm}$ [8]. These studies used silver nitrate as a source of silver, and they used the sol-gel method at a low temperature, so that it was shown that the formation of $\mathrm{Ag}_{2} \mathrm{O}$ arose from electrostatic attraction to HA. In a study by Rameshbabu et al., antibacterial Ag-HA was synthesized by the microwave method, and it was determined from the XRD results that all patterns corresponded to the hexagonal crystals of HA in the JCPDS 9-432 database, and were almost the same [11]. However, they reported that in samples where the amount of silver was over $x \geq 0.4$, the $2 \theta \sim 36.68^{\circ} \quad\left(\mathrm{Ag}_{3} \mathrm{PO}_{4}\right.$, JCPDS 6-505) silver phosphate peaks were not clearly visible. The $0-5 \%$ Ag-HA obtained in the present study was not subjected to any heat treatment other than drying in an oven at $100{ }^{\circ} \mathrm{C}$. As the amount of silver attaching to the HA under these conditions was $5 \%$, no impurity phase was encountered apart from observation of the $\mathrm{Ag}_{2} \mathrm{O}$ phase.

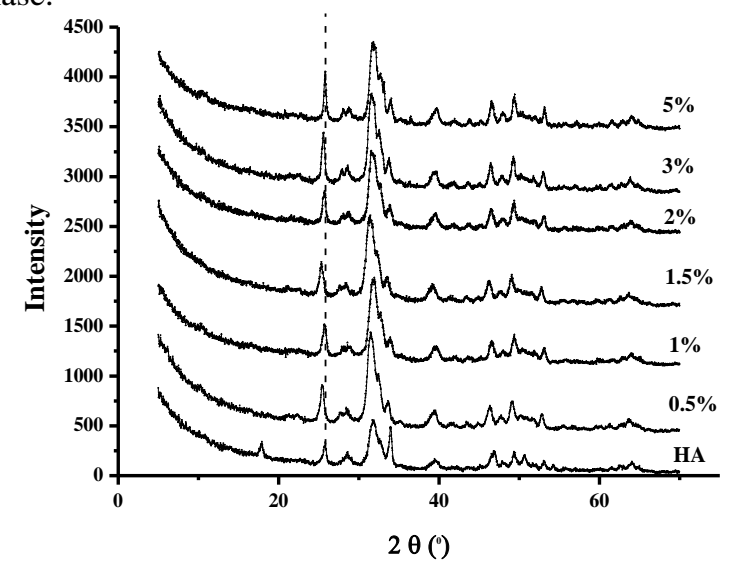

Fig. 1. XRD patterns of the $0 \%-5 \%$ Ag-HA

\subsection{Scanning electron microscope (SEM) analysis}

Fig. 2 shows the results of SEM analysis of the synthesized pure HA and Ag-HA.

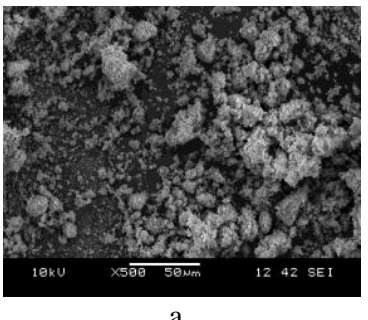

a

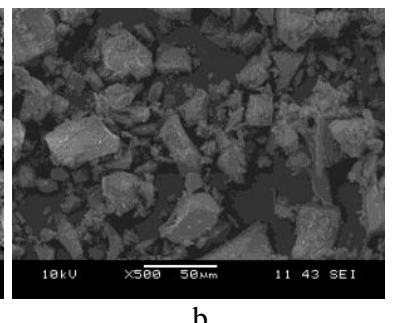

b
Fig. 2. SEM micrographs of HA (a) and $1.5 \% \mathrm{Ag}-\mathrm{HA}$ (b)

In images taken by the secondary electron imaging technique of the scanning electron microscope, powder containing pure HA had fine and rounded lines, while AgHa powder showed morphologically more distinct lines. The results of SEM analysis showed that when the microstructure obtained was analyzed the powders generally had a particle size of $50 \mu \mathrm{m}$ or less (Fig. 2). It was seen that the synthesized HA powder did not show a 
homogeneous distribution because it had been ground manually in a mortar. It was determined that as the size of the particles in the powders in the study decreased, they tended to come together and form agglomerates in order to reduce the increasing surface energies.

Authors found that the average particle size in Ag-HA which they obtained by the sol-gel method was between 3 and $19 \mu \mathrm{m}$ [8]. Others stated that particles of pure HA and $0.5 \%$ Ag-HA synthesized with the use of microwaves were needle-shaped and showed a great tendency to flocculate [10]. However, they reported that $5 \% \mathrm{Ag}-\mathrm{HA}$ particles formed more regular lines and heaped up less, which could be an effect of the silver phosphate phase around them. The SEM results obtained in the present study show that particles of Ag-HA produced by the microwave method were small in dimensions and had a homogeneous distribution.

\subsection{Energy dispersive X-ray spectroscopy analysis}

The effective antimicrobial agent trapped in the crystal structure of the powder, that is the silver cations, were determined using Energy dispersive X-ray spectroscopy (EDS). Results are shown in Fig. 3. The values obtained by EDS were compared with stoichiometric values measured during powder production, and it was found that the $\mathrm{Ca} / \mathrm{P}$ ratio in the sample of pure HA (1.667) was close to the stochiometric $\mathrm{HA}$ ratio $(\mathrm{Ca} / \mathrm{P}=1.67)$, and that this ratio was 1.573 in the sample of $1 \%$ Ag-HA (Fig. 3). In addition, elemental analysis ascertained the presence of $\mathrm{Ag}$ in Ag-HA.

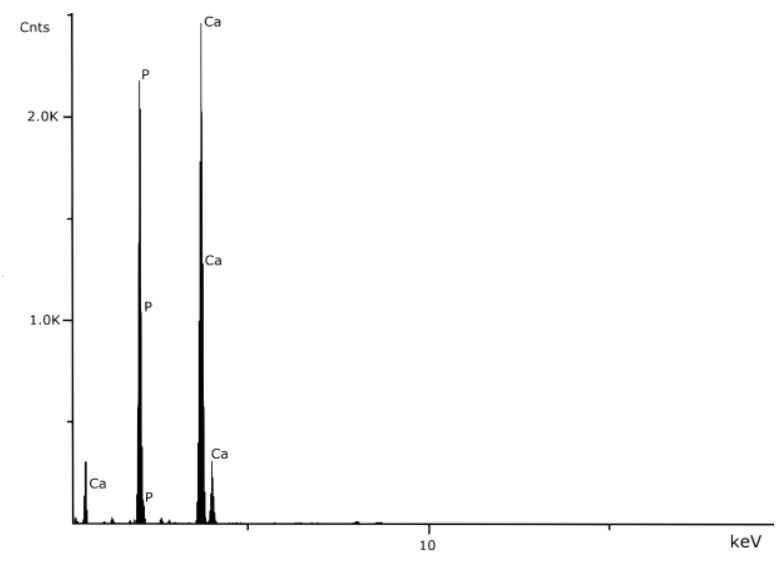

a

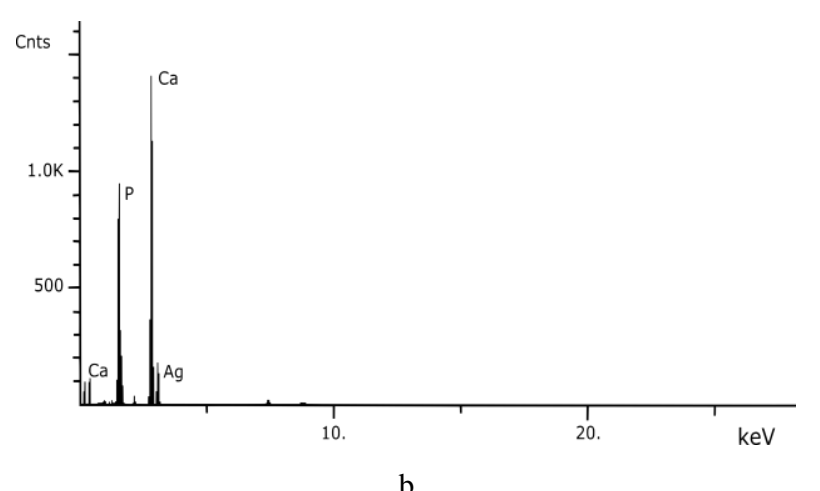

b

Fig. 3. SEM/EDS spectra of HA (a) and $1.0 \%$ Ag-HA (b)

Feng et al. examined the morphology and composition of Ag-HA coating by SEM and EDS, and found that the
$\mathrm{Ca} / \mathrm{P}$ atomic ratios of silver-doped and non-silver-doped coatings were 1.19 and 1.46 respectively [17]. The researchers concluded that the $\mathrm{Ca}^{2+}$ ions in the $\mathrm{HA}$ structure had been exchanged for $\mathrm{Ag}^{+}$ions. In the present study, it was thought that the difference found in the $\mathrm{Ca} / \mathrm{P}$ ratios in the $1 \% \mathrm{Ag}-\mathrm{Ha}$ sample may stem from the exchange of places of the $\mathrm{Ca}$ ions in the HA cage with $\mathrm{Ag}$ ions, and losses during the heat treatment at the time of synthesis of the powders.

\subsection{ICP-OES analysis}

A determination of the silver content of Ag-HA was performed by ICP-OES analysis, and the values for pure $\mathrm{HA}$ and Ag-HA are given in Fig. 4. According to these results, the ICP values are in proportion to the previously calculated amounts of silver (pure HA, $0.5 \% \mathrm{Ag}-\mathrm{HA}$ and $1 \% \mathrm{Ag}-\mathrm{HA}$ ) and as the amount of silver increased, so this ratio increased in proportion (2\% Ag-Ha and $3 \% \mathrm{Ag}-\mathrm{HA}$ ). It was observed that the amounts of $\mathrm{Ag}$ doped into the hydroxyapatite structure also showed differences according to the HA ion exchange capacity (5\% Ag-HA).

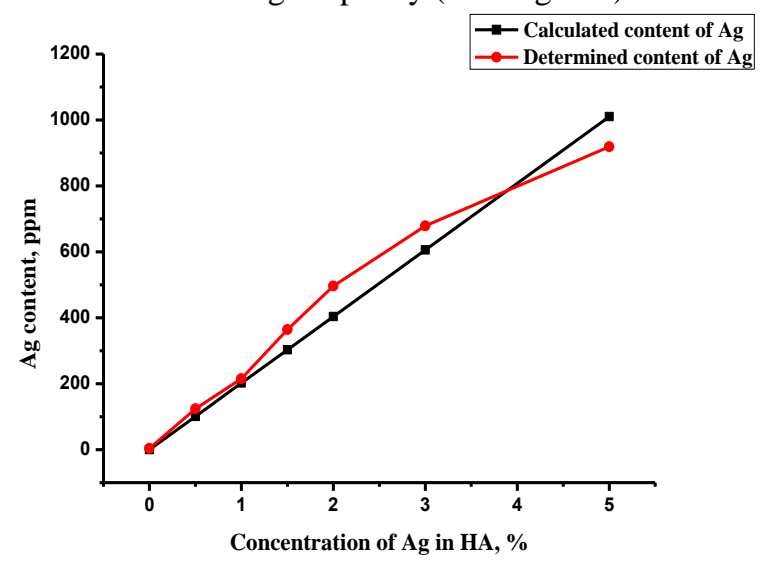

Fig. 4. Amounts of Ag in HA samples

Oh et al. doped $\mathrm{Ag}$ ions into HA powder by immersion in a solution of $\mathrm{AgNO}_{3}$, and reported that although a slight increase in the amount of doped silver was observed with the increase in the arranged amount of silver, after drying by evaporation $2.21 \%$ of $\mathrm{Ag}$, and after freeze drying $4.87 \%$ of $\mathrm{Ag}$, were doped, the opposite to the assumption that the HA would ion-exchanged with $15 \%$ of the Ag out of the total moles of cations [7]. In another study, the amount of $\mathrm{Ag}$ in $\mathrm{Ag}-\mathrm{HA}$ obtained by the precipitation method was determined using an ICP apparatus, and an increase in the amount of doping $\mathrm{Ag}$ was observed with an increase in the $\mathrm{Ag} / \mathrm{Ca}$ ratio [9]. It was found that the $\mathrm{Ag}$ concentration in the HA was not in accord with the concentrations in the starting materials; however, the values were within acceptable deviation ratios, and most importantly, increases were found [8]. In our study, there was an increase in the amounts of silver calculated for Ag$\mathrm{HA}$ and doped $\mathrm{Ag}$, and it is thought that this came about as a result of ion exchange between $\mathrm{Ag}$ ions and $\mathrm{Ca}$ ions in the $\mathrm{HA}$ cage causing a reduction in $\mathrm{Ca}$ ions and an increase in $\mathrm{Ag}$ ions. However, when the amount of $\mathrm{Ag}$ in the HA was $5 \%$, a reduction in the amount of doped $\mathrm{Ag}$ indicated that the amount of exchangeable $\mathrm{Ca}^{2+}$ ions in the hydration layer of the HA was only about $4 \%$ of the total $\mathrm{Ca}^{2+}$ ions in the crystals. 


\subsection{Findings of FTIR analysis}

Table 1 shows spectra and observed functional groups which characterize the bond structures of HA and silverdoped HA powders, as obtained by FTIR. FTIR spectra showed that the $v_{1} \mathrm{PO}_{4}{ }^{3-}$ band around $962 \mathrm{~cm}^{-1}$, the $v_{2} \mathrm{PO}_{4}{ }^{3-}$ band around $472 \mathrm{~cm}^{-1}$, the $v_{3} \mathrm{PO}_{4}{ }^{3-}$ band around 1025 and $1090 \mathrm{~cm}^{-1}$ and the $v_{4} \mathrm{PO}_{4}^{3-}$ band around 562, 559 and $601 \mathrm{~cm}^{-1}$ are the important characteristic bands of hydoxyapatite, and the sharp peaks at 3570 and $632 \mathrm{~cm}^{-1}$ were the $\mathrm{O}-\mathrm{H}$ band (Table 1 ).

It was determined that bands at $\sim 1090$ and $962 \mathrm{~cm}^{-1}$ reflected the P-O vibration modes indicating a weakly crystallized hydroxyapatite structure, and that the band at $\sim 602 \mathrm{~cm}^{-1}$ reflected the hydroxyapatite peaks which correspond to the tension modes of $\left(\mathrm{PO}_{4}\right)^{3-}$ ions [18]. Su and Xiong examined the FTIR spectra of HA heat-treated at $600{ }^{\circ} \mathrm{C}$ and $\mathrm{Ag}$-HA which had not undergone heat treatment, and reported that the sharp peaks at 3571 and $631 \mathrm{~cm}^{-1}$ were related to $\mathrm{O}-\mathrm{H}$ vibration, and that the peaks at $1090,1041,962.601,567$ and $474 \mathrm{~cm}^{-1}$ reflected $\mathrm{PO}_{4}{ }^{3-}$ vibration [19]. Rameshbabu et al. observed the characteristic peaks for HA in the spectra of Ag-HA dried in an oven and heat-treated at $900{ }^{\circ} \mathrm{C}$ in two samples, $\mathrm{PO}_{4}{ }^{3-}$ tension and bending modes at $900-1200 \mathrm{~cm}^{-1}, \mathrm{PO}_{4}{ }^{3-}$ bending mode at $602 \mathrm{~cm}^{-1}$, and $-\mathrm{OH}$ vibration mode at 632 and $3571 \mathrm{~cm}^{-1}$ [11].

Table 1. The functional groups in FTIR spectra of the $0 \%-5 \%$ $\mathrm{Ag}-\mathrm{HA}$ in as synthesized condition

\begin{tabular}{|l|c|c|c|c|c|c|c|c|}
\hline \multirow{2}{*}{$\begin{array}{l}\text { Functional } \\
\text { groups }\end{array}$} & $\mathrm{HA}$ & $\begin{array}{c}0.5 \% \\
\mathrm{Ag}-\mathrm{HA}\end{array}$ & $\begin{array}{c}1 \% \\
\mathrm{Ag}-\mathrm{HA}\end{array}$ & $\begin{array}{c}1.5 \% \\
\mathrm{Ag}-\mathrm{HA}\end{array}$ & $\begin{array}{c}2 \% \\
\text { Ag-HA }\end{array}$ & $\begin{array}{c}3 \% \\
\text { Ag-HA }\end{array}$ & $\begin{array}{c}5 \% \\
\text { Ag-HA }\end{array}$ \\
\cline { 2 - 8 } & \multicolumn{6}{|c|}{ Wavenumber, cm-1 } \\
\hline $\begin{array}{l}v_{2} \mathrm{PO}_{4} \\
\text { vibration } \\
\text { band* }\end{array}$ & 471 & 471 & 471 & 471 & 471 & 471 & 472 \\
\hline $\begin{array}{l}v_{4} \mathrm{PO}_{4} \\
\text { vibration } \\
\text { band }\end{array}$ & 562 & 563 & 560 & 562 & 562 & 559 & 562 \\
\hline $\begin{array}{l}v_{4} \mathrm{PO}_{4} \\
\text { vibration } \\
\text { band }\end{array}$ & 600 & 602 & 601 & 601 & 602 & 601 & 601 \\
\hline $\begin{array}{l}v_{1} \mathrm{PO}_{4} \\
\text { vibration } \\
\text { band }\end{array}$ & 962 & 962 & 962 & 962 & 962 & 962 & 962 \\
\hline $\begin{array}{l}v_{3} \mathrm{PO}_{4} \\
\text { vibration } \\
\text { band }\end{array}$ & 1025 & 1025 & 1025 & 1024 & 1024 & 1024 & 1023 \\
\hline -OH band & 632 & 632 & 632 & 633 & 632 & 631 & 632 \\
\hline $\begin{array}{l}v_{3} \mathrm{PO}_{4} \\
\text { vibration } \\
\text { band }\end{array}$ & 1090 & 1090 & 1090 & 1090 & 1090 & 1090 & 1090 \\
\hline -OH band & 3570 & & & & & & \\
\hline *not shown in Fig. 5. & & & & & & \\
\hline
\end{tabular}

Shirkhanzadeh at al. stated that no extra peaks were observed in the FTIR spectrum between the wavelengths of 400 and $4000 \mathrm{~cm}^{-1}$ when HA was doped with $\mathrm{Ag}$ [20]. Nath et al. stated that the $\mathrm{Ag}-\mathrm{O}$ band of $\mathrm{Ag}_{2} \mathrm{O}$ and $\mathrm{AgO}$ phases could not be detected by the $400-4000 \mathrm{~cm}^{-1}$ wavelength FTIR scanning limit and therefore apart from the $\mathrm{O}-\mathrm{H}$ vibration peak change at $3570 \mathrm{~cm}^{-1}$, FTIR results did not show the presence of silver ions [21]. Thus, it was shown that the O-H group in the HA cage is modified by the presence of an Ag ion. In our study, the characteristic peaks for hydroxyapatite in the FTIR spectra of both pure
HA and Ag-HA were in accordance with the literature. However, the $3570 \mathrm{~cm}^{-1}$ peak for the hydroxyl group in the FTIR spectrum of the compound Ag-HA was not observed (Fig. 5). It is thought that the reason for this is that as explained above, the silver substitutions in the HA take place in accordance with the formula $\mathrm{Ca}_{9} \mathrm{Ag}_{\mathrm{x}}\left(\mathrm{PO}_{4}\right)_{6}(\mathrm{OH})_{2}$.

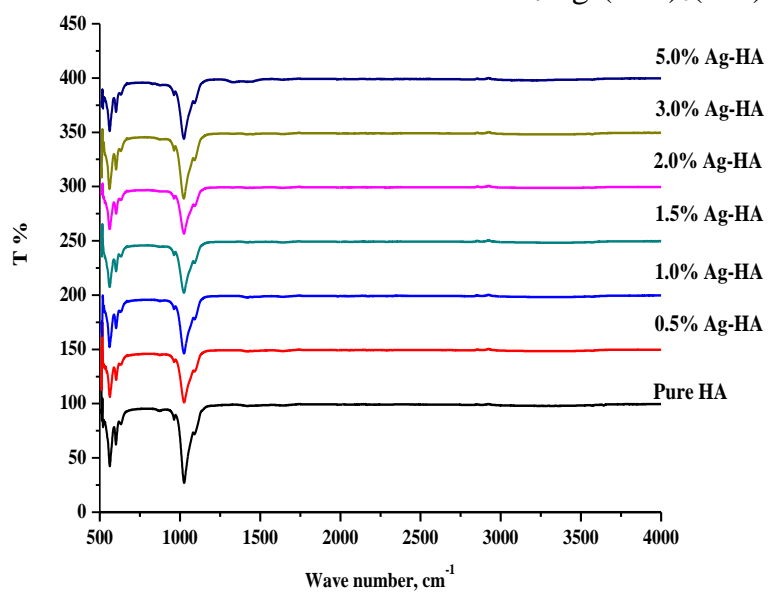

Fig. 5. FTIR spectra of the $0 \%-5 \%$ Ag-HA

\subsection{Results of MIC values of $0-5 \%$ Ag-HA solutions}

The calculated MIC values of solutions of pure HA and $0.5-5 \%$ Ag-HA against gram-negative and grampositive bacteria and $C$. albicans are given in Table 2. According to the results obtained, pure $\mathrm{HA}$ and $0.5 \% \mathrm{Ag}-$ HA showed no antimicrobial activity to any of the test organisms, while solutions of $1-5 \%$ Ag-HA showed different activities according to the species of microorganism. Effective MIC values against gramnegative bacteria were $2.09-12.25 \mu \mathrm{g} / \mathrm{ml}$, and against gram-positive bacteria and $C$. albicans they were $4.18-12.25 \mu \mathrm{g} / \mathrm{ml}$. MIC concentrations effective against the gram-negative bacteria $K$. pneumoniae and $P$. aeruginosa were recorded respectively as $2.09-5.38$ and $2.09-9.10 \mu \mathrm{g} / \mathrm{ml}$.

Table 2. MIC values of $0-5 \%$ solutions of $\mathrm{Ag}-\mathrm{HA}$ against bacteria and C. albicans $(\mu \mathrm{g} / \mathrm{mL})$

\begin{tabular}{|l|c|c|c|c|c|c|c|}
\hline & $\mathrm{HA}$ & $\begin{array}{c}0.5 \% \\
\text { Ag-HA }\end{array}$ & $\begin{array}{c}1 \% \\
\text { Ag-HA }\end{array}$ & $\begin{array}{c}1.5 \% \\
\text { Ag-HA }\end{array}$ & $\begin{array}{c}2 \% \\
\text { Ag-HA }\end{array}$ & $\begin{array}{c}3 \% \\
\text { Ag-HA }\end{array}$ & $\begin{array}{c}5 \% \\
\text { Ag-HA }\end{array}$ \\
\hline E. coli & - & - & 10.76 & 9.10 & 6.12 & 8.37 & 11.50 \\
\hline $\begin{array}{l}\text { S. } \\
\text { typhimirium }\end{array}$ & - & - & 10.76 & 9.10 & 12.25 & 8.37 & 11.50 \\
\hline P.aeruginosa & - & - & 5.38 & 4.55 & 6.12 & 2.09 & 2.87 \\
\hline K.pneumoniae & - & - & 5.38 & 9.10 & 3.06 & 2.09 & 2.87 \\
\hline S.aureus & - & - & 10.76 & 9.10 & 6.12 & 4.18 & 5.75 \\
\hline B.subtilis & - & - & 10.76 & 9.10 & 12.25 & 8.37 & 5.75 \\
\hline E. faecalis & - & - & 10.76 & 9.10 & 6.12 & 4.18 & 5.75 \\
\hline C.albicans & - & - & 10.76 & 9.10 & 6.12 & 4.18 & 5.75 \\
\hline
\end{tabular}

Feng et al. examined the antibacterial effect of a thin film of Ag-HA on an aluminium substrate against gramnegative $E$. coli and $P$. aeruginosa and gram-positive $S$. aureus and $S$. epidermidis, and it was determined that a $12.7 \mathrm{ppm}$ concentration of $\mathrm{Ag}$ in $\mathrm{HA}$ prevented reproduction of the test bacteria on the aluminium substrate, and killed the bacteria [17].

$\mathrm{Oh}$ et al. compared the MIC values of Ag-HA obtained by the ion-exchange and precipitation methods against the 
gram-positive $S$. aureus and the gram-negative $E$. coli bacteria, and determined that as the amount of silver increased, the MIC values of Ag-HA prepared by both methods against both bacteria was effective at higher concentrations [9]. However, differences were observed in the MIC values against both bacteria between Ag-HA with approximately the same amount of silver according to the synthesis method. Nirmala et al. stated that the bactericidal effects of $\mathrm{Ag}-\mathrm{HA}$ were more pronounced with an increased amount of $\mathrm{Ag}$, and that $\mathrm{HA}$ containing $1 \%$ of silver showed an MIC value against $S$. aureus varieties which were either resistant or susceptible to methicillin, while HA containing $3 \%$ silver showed an MIC value against $E$. coli [22].

Two mechanisms have been developed to explain the antimicrobial effects of Ag-HA. First, that microorganisms adhere to the surface by electrostatic force and interact directly with metal ions. The second mechanism is that the slow release of $\mathrm{Ag}$ from $\mathrm{HA}$ can inhibit bactericidal activity in the medium [23-25].

Several studies have been carried out to demonstrate the antimicrobial activity of Ag-HA powders as well as the surfaces of Ag-HA coatings against a broad range of microorganisms, especially bacteria, and different results have been obtained $[23,26,27,28]$. The broad antibacterial spectrum of Ag-HA is similar to the spectrum of silver ions, and like silver ions, it has a more effective influence on gram-negative rather than gram-positive bacteria [26]. The reason for different sensitivities between gram-positive and gram-negative bacteria and C. albicans can be found in the different transparencies of the cell wall [29]. The cell wall of gram-positive bacteria consists of peptidoglucans (mureins) and teichoic acids, while the cell wall of gram-negative bacteria consists of lipo polysaccharides and lipopolyproteins, and that of fungi consists of polysaccharides such as hitchin and glucan $[30,31]$.

Apart from this, the antimicrobial effects of Ag-HA may be associated with the characteristics of specific bacterial strains. Thus, Bai et al. (2012) reported that a higher content of $\mathrm{Ag}$ in functionally graded HA coatings particularly $3 \%$ and $6.5 \mathrm{wt} . \%$ caused a reduction in the viability of $S$. aureus (Cowan I strain, ATCC 12598), as opposed to 1 wt.\% of Ag [27]. Chen et al. (2007) evaluated the surface of Ag-HA coatings against S. aureus (Cowan I) and observed the reduced adhesion of $S$. aureus on $1 \%$ Ag-HA when compared to a $1.5 \%$ Ag-HA coating [26]. Samani et al. (2013) determined that $1.5 \%$ of Ag in an HA coating has a strong antibacterial effect against $S$. aureus (Methicillin-resistant) due to the powerful antibacterial property of Ag [23]. Also, Ciobanu et al. (2011) revealed lower adhesion of $S$. aureus (ATCC 6538) on nano-sized $\mathrm{xAg}-\mathrm{HA}$ powder with $\mathrm{x}=0.2$ content of $\mathrm{Ag}$ [28].

The reported results are higher than those obtained by us in the present study, which suggests that the antimicrobial activity of Ag-HA may be influenced by the bacterial strains used as well as by the preparation method. The method of preparation or the possible treatments results in apatites, which have a characteristic degree of crystallinity and a specific surface area. It is well known that the antibacterial activity of silver ions increases with surface area, due to its extent of release from the apatite.
Therefore, the methods by which the fine crystals are obtained lead to obtaining a material displaying more powerful antibacterial activity [25]. Thus, the relationship between the method of synthesis of the Ag-HA and its antimicrobial effect should also be examined.

\section{CONCLUSIONS}

In this study, an investigation was made of the antimicrobial effectiveness of silver-doped hydroxyapatite synthesized by the microwave method. The physical, chemical and structural characteristics of the material were determined using multi-purpose X-ray diffractometry (XRD), Fourier transform infrared spectrometry (FTIR), and scanning electron microscope-energy dispersive X-ray spectroscopy (SEM-EDS) apparatus. The amount of silver in the solutions of silver-doped hydroxyapatite obtained were determined with the use of an inductively coupled plasma optical emission spectroscopy instrument (ICPOES), and it was established that the amount of added silver and the calculated amount were proportional. The effective concentrations of the silver-doped hydroxyapatite against test microorganisms was determined by means of the broth microdilution technique, and the effective MIC value against gram-negative bacteria (E. coli, $S$. thyphimurium, $P$. aeruginosa and $K$. pneumoniae) was found to be $2.09-12.25 \mu \mathrm{g} / \mathrm{ml}$, and against gram-positive bacteria ( $S$. aureus, B. subtilis, and E. faecalis) and $C$. albicans it was $4.18-12.25 \mu \mathrm{g} / \mathrm{ml}$. In the light of these results, future studies will concern $\mathrm{Ag}-\mathrm{HA}$ as an antibacterial coating additive on leather.

\section{Acknowledgement}

We would like to thank the Research Foundation of Ege University for their financial support (Project No 09MÜH080).

\section{REFERENCES}

1. Kim, T.N., Feng, Q.L., Wu, J., Wang, H., Chen, G.C., Cui, F.Z. Antimicrobial Effects of Metal Ions $\left(\mathrm{Ag}^{+}, \mathrm{Cu}^{2+}\right.$, $\mathrm{Zn}^{2+}$ ) in Hydroxyapatite Journal of Materials Science: Materials in Medicine 9 1998: pp. 129-134. http://dx.doi.org/10.1023/A:1008811501734

2. Kawashita, M., Tsuneyama, S., Miyaji, F., Kokubo, T., Kozuka, H., Yamamoto, K. Antibacterial Silver-Containing Silica Glass Prepared By Sol-Gel Method Biomaterials 21 2000: pp. 393-398.

3. Correria, R.N., Magalhaes, M.C., Marques, P.A.P.P., Senos, A.M.R. Wet Synthesis and Characterisation of Modified Hydroxyapatite Powders Journal of Materials Science 7 1996: pp. 501-505.

4. Katsuki, H., Furuta, S., Komarneni, S. Microwave versus Conventional Hydrothermal Synthesis of Hydroxyapatite Crystals from Gypsum Journal of the American Ceramic Society 82 1999: pp. 2557-2559.

5. Liu, D.M. Preparation and Characterisation of Porous Hydroxyapatite Bioceramic via a Slip-Casting Route Ceramics International 24 1998: pp. 441-446. http://dx.doi.org/10.1016/S0272-8842(97)00033-3

6. Hench, L., Wilson, J. An Introduction to Bioceramics. World Scientific, Singapore, 1993: p. 396. http://dx.doi.org/10.1142/2028 
7. Oh, K.S., Kim, K.J., Jeong, Y.K., Choa, Y.H. Effect of Fabrication Processes on the Antimicrobial Properties of Silver Doped Nano-Sized Hap Key Engineering Materials 240-242 2003: pp. 583-586.

8. Chung, R.J., Hsieh, M.F., Huang, C.W., Perng, L.H., Chou, F.I., Chin, T.S. Anti-Microbial Hydroxyapatite Particles Synthesized by a Sol-Gel Route Journal of SolGel Science and Technology 33 2005: pp. 229-239. http://dx.doi.org/10.1007/s10971-005-5618-1

9. Oh, K.S., Park, S.H., Jeong, Y.K. Durability in Antimicrobial Effects of Silver Doped Hydroxyapatite Depending on the Synthesis Route Materials Science Forum 449-452 2004: pp. 1233-1236.

10. National Committee for Clinical Laboratory Standards, Wayne, Pa, 1993.

11. Rameshbabu, N., Sampath Kumar, T.S., Prabhakar, T.G., $\quad$ Sastry, V.S., $\quad$ Murty, K.V.G.K., Prasad Rao, K. Antibacterial Nanosized Silver Substituted Hydroxyapatite: Synthesis and Characterization Journal of Biomedical Materials Research Part A 80 (3) 2006: pp. 581-591.

12. Olson, C.R., Balasubramaniam, T., Shrum, J., Nord, T., Taylor, P.L., Burrell, R.E. Novel Antimicrobial Activity of Nanocrystalline Silver Dressings. Proceedings of International Conference on MEMS, NANO and Smart Systems Alberta Canada 2005: pp. 129-131. http://dx.doi.org/10.1109/icmens.2005.90

13. Sarkar, S., Jana, A.D., Samanta, S.K., Mostafa, G. Facile Synthesis of Silver Nano Particles with Highly Efficient Anti-Microbial Property Polyhedron 26 2007: pp. 4419-4426.

14. Holetz, B., Pessini, G.L., Sanches, N.R., Garcia Cortez, D.A., Nakamura, C.V., Dias Filho, B.P. Screening of Some Plants Used in the Brazilian Folk Medicine for the Treatment of Infectious Diseases Mem Inst Oswaldo Cruz Rio de Janeiro 97(7) 2002: pp. 1027-1031.

15. Yaşa, I., Lkhagvajav, N., Koizhaiganova, M., Çelik, E., Sar, Ö. Assessment of Antimicrobial Activity of NanoSized $\quad \mathrm{Ag}_{-} \mathrm{TiO}_{2}$ Prepared by Sol-Gel Method World Journal of Microbiology and Biotechnology 28 2012: pp. $2531-2539$. http://dx.doi.org/10.1007/s11274-012-1061-y

16. JCPDS (2001) (Joint Committee on Powder Diffraction Standards) Database, International Centre for Diffraction Data.

17. Feng, Q.L., Kim, T.N., Wu, J., Park, E.S., Kim, J.O., Lim, D.Y., Cui, F.Z. Antibacterial Effects of Ag-Hap Thin Flms on Alumina Substrates Thin Solid Films 335 1998: pp. 214-219.

18. Wang, Y., Wang, X., Wei, K., Zhao, N., Zhang, S., Chen, J. Fabrication, Characterization and Long Term In Vitro Release of Hydrophilic Drug Using PHBV/HA Composite Microspheres Materials Letters 61 2007: pp. 1071-1076. http://dx.doi.org/10.1016/j.matlet.2006.06.062

19. Su, B.H., Xiong, Z.X. Preparation of Antibacterial Ceramics with Silver-Carrying Nano-Hydroxyapatite Key Engineering Materials 336-338 2007: pp. 1563-1566.

20. Shirkhanzadeh, M., Azadegan, M., Liu, G.Q. Bioactive Delivery Systems for the Slow Release of Antibiotics:
Incorporation of $\mathrm{Ag}^{+}$Ions into Micro-Porous Hydroxyapatite Coatings Materials Letters 24 1995: pp. 7-12. http://dx.doi.org/10.1016/0167-577X(95)00059-3

21. Nath, S., Kalmodia, S., Basu, B. Densification, Phase Stability and In Vitro Biocompatibility Property of Hydroxyapatite-10 w.t\% Silver Composites Journal of Materials Science: Materials in Medicine 21 2010: pp. $1273-1287$.

http://dx.doi.org/10.1007/s10856-009-3939-2

22. Nirmala, R., Sheikh, F.A., Kanjwal, M.A., Lee, J.H., Park, S.J., Navamathavan, R., Kim, H.Y. Synthesis and Characterization of Bovine Femur Bone Hydroxyapatite Containing Silver Nanoparticles for The Biomedical Applications Journal of Nanoparticle Research 13 (5) 2010: pp. $1917-1927$.

23. Samani, S., Hossainalipour, S.M., Tamizifar, M., Rezaie, H.R. In Vitro Antibacterial Evaluation of Sol-Gel Derived Zn-, Ag-, and ( $\mathrm{Zn}+\mathrm{Ag})$-Doped Hydroxyapatite Coatings Against Methicillin-Resistant Staphylococcus aureus Journal of Biomedical Materials Research Part A 101A 2013: pp. 222-230.

http://dx.doi.org/10.1002/jbm.a.34322

24. Li, J.D., Li, Y.B., Zuo, Y., Lv, G.Y., Yang, W.H., Tian, Zh.Y. Antibacterial Effect and Security Evaluation on Nano-Hydroxyapatite Bearing $\mathrm{Cu}^{2+}$ and $\mathrm{Zn}^{2+}$ Materials Science Forum 510-511 2006: pp. 890-893.

25. Kolmas, J., Groszyk, E., Kwiatkowska-Róhycka, D. Substituted Hydroxyapatites with Antibacterial Properties BioMedical Research International 2014: pp. 1-5.

26. Chen, W., Oh, S., Ong, A.P., Oh, N., Liu, Y., Courtney, H.S., Appleford, M., Ong, J.L. Antibacterial and Osteogenic Properties of Silver-Containing Hydroxyapatite Coatings Produced Using a Sol Gel Process Journal of Biomedical Materials Research Part A 82 (4) 2007: pp. 899-906.

27. Bai, X., Sandukas, S., Appleford, M., Ong, J.L., Rabiei, A. Antibacterial Effect and Cytotoxicity of AgDoped Functionally Graded Hydroxyapatite Coatings Journal of Biomedical Materials Research Part B 100B 2012: pp. $553-561$. http://dx.doi.org/10.1002/jbm.b.31985

28. Ciobanu, C.S., Massuyeau, F., Constantin, L.V., Predoi, D. Structural and Physical Properties of Antibacterial Ag-Doped Nano-Hydroxyapatite Synthesized at $100^{\circ} \mathrm{C} \quad$ Nanoscale Research Letters 6 2011: pp. $613-620$. http://dx.doi.org/10.1186/1556-276X-6-613

29. Yang, Y., Anderson, E.J. Antimicrobial Activity of a Porcine Myeloperozidase against Plant Pathogenic Bacteria and Fungi Journal of Applied Microbiology 86 1999: pp. $211-220$.

30. vanHeijenoort, J. Formation of The Glycan Chains in the Synthesis of Bacterial Peptidoglycan Glycobiology 11 2001: pp. $25-36$.

31. Farkaš, V. Structure and Biosynthesis of Fungal Cell Walls: Methodological Approaches Folia Microbiology 48 2003: pp. 469-478. http://dx.doi.org/10.1007/BF02931327 